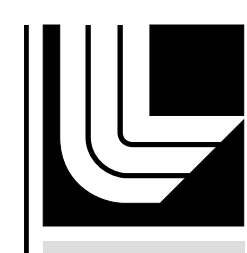

LAWRENCE LIVERMORE N A T IO N A L LABORATORY

\title{
SHOCK INITIATION OF COMPOSITION B AND C-4 EXPLOSIVES; EXPERIMENTS AND MODELING
}

P. A. Urtiew, K. S. Vandersall, C. M. Tarver, F. Garcia, J. W. Forbes

August 21, 2006

International Conference on Shock Waves in Condensed Matter

Saint Petersburg, Russia

September 3, 2006 through September 8, 2006 
This document was prepared as an account of work sponsored by an agency of the United States Government. Neither the United States Government nor the University of California nor any of their employees, makes any warranty, express or implied, or assumes any legal liability or responsibility for the accuracy, completeness, or usefulness of any information, apparatus, product, or process disclosed, or represents that its use would not infringe privately owned rights. Reference herein to any specific commercial product, process, or service by trade name, trademark, manufacturer, or otherwise, does not necessarily constitute or imply its endorsement, recommendation, or favoring by the United States Government or the University of California. The views and opinions of authors expressed herein do not necessarily state or reflect those of the United States Government or the University of California, and shall not be used for advertising or product endorsement purposes. 
Draft Paper for the International Conference on

"Shock Waves in Condensed Matter"

Saint Petersburg, Russia

September $3-$ 8, 2006

\title{
SHOCK INITIATION OF COMPOSITION B AND C-4 EXPLOSIVES; EXPERIMENTS AND MODELING *
}

\author{
Paul A. Urtiew ${ }^{1}$, Kevin S. Vandersall ${ }^{1}$, Craig M. Tarver ${ }^{1}$, \\ Frank Garcia ${ }^{1}$, and Jerry W. Forbes ${ }^{2}$ \\ ${ }^{1}$ Energetic Materials Center, Lawrence Livermore National Laboratory, Livermore, CA 94550 \\ ${ }^{2}$ Center for Energetic Concepts Development, University of Maryland, College Park, MD 20742
}

\begin{abstract}
Shock initiation experiments on the explosives Composition B and C-4 were performed to obtain in-situ pressure gauge data for the purpose of providing the Ignition and Growth reactive flow model with proper modeling parameters. A $100 \mathrm{~mm}$ diameter propellant driven gas gun was utilized to initiate the explosive charges containing manganin piezoresistive pressure gauge packages embedded in the explosive sample. Experimental data provided new information on the shock velocity particle velocity relationship for each of the investigated material in their respective pressure range. The run-distance-to-detonation points on the Pop-plot for these experiments showed agreement with previously published data, and Ignition and Growth modeling calculations resulted in a good fit to the experimental data. Identical ignition and growth reaction rate parameters were used for $\mathrm{C}-4$ and Composition $\mathrm{B}$, and the Composition $\mathrm{B}$ model also included a third reaction rate to simulate the completion of reaction by the TNT component. This model can be applied to shock initiation scenarios that have not or cannot be tested experimentally with a high level of confidence in its predictions.
\end{abstract}

\section{Introduction}

Shock initiation is one of the most important properties of energetic materials (EM). Of interest here is the determination whether the input shock wave will build in pressure to a full-fledged detonation or decay to a deflagration wave or to a non-reacting wave. So the study of this property is important to gain knowledge if a material will detonate as intended or not for different dynamic loadings.

*This work was performed under the auspices of the U. S. Department of Energy by the University of California, Lawrence Livermore National Laboratory under Contract No. W-7405-Eng-48. 
Energetic materials are widely used in both industrial and military applications. Therefore, initiation of such materials is of particular interest for reasons of safety and understanding of their behavior under dynamic loading conditions.

In earlier publications we have reported initiation thresholds for build up to detonation and sensitivity to impact (Pop-plots) of both sensitive and insensitive, HMX and TATB based explosives at various initial temperatures $(1,2)$. In this publication we will report on initiation and sensitivity of more common RDX based explosives known as C-4 and Composition B and will include previously unpublished manganin gauge records for sustained pulse shock initiation.

\section{Experimental Technique}

Most of the experiments in our laboratory are performed on the $100 \mathrm{~mm}$ bore, propellant driven gas gun, which allows precise control of the projectile velocity and of the loading pressure imposed on the EM target. The experimental set-up is illustrated in Fig 1.
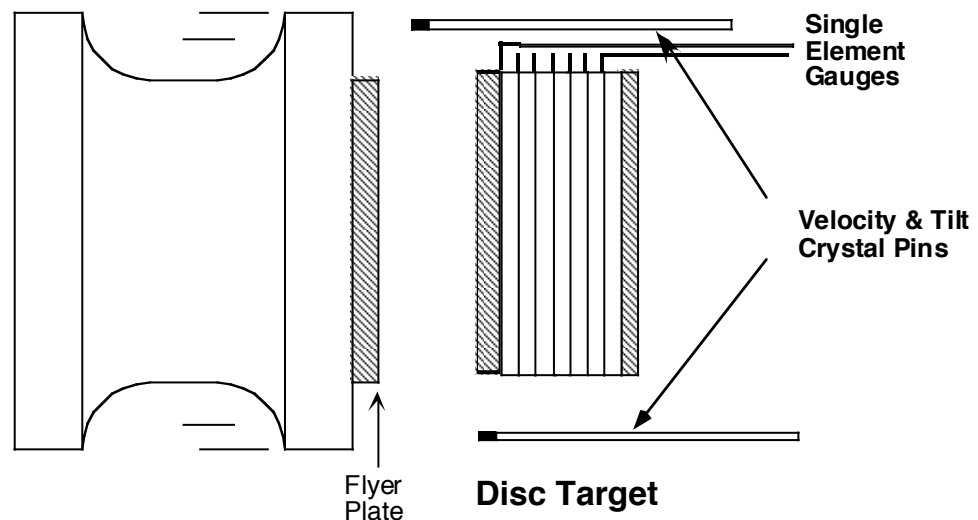

Sabot

Disc Target

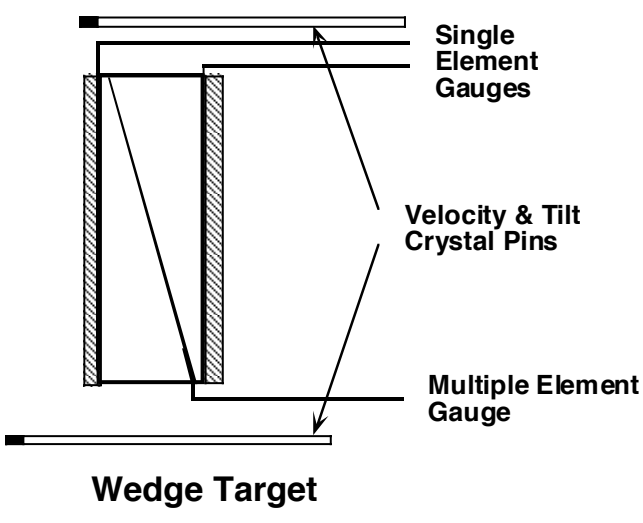

Figure 1. Schematic diagram of experimental set-up for gun experiments

There were two types of target assemblies that were used in these experiments. One target assembly consisted of several discs of different thicknesses. Gauge packages containing manganin pressure gauges were embedded between individual discs. The other target assembly consisted of two $24^{\circ}$ wedges with one multi-element pressure gage 
package placed between them. The intent here was to eliminate the effect of inert package material on each consecutive gauge element. The gauges are armored with thin $(125 \mu \mathrm{m})$ Teflon insulation on both sides to prevent shorting of the gauges in a conductive medium when the material becomes reactive. Other details of the manganin pressure gauges are described in our previous publications $(3,4)$.

For better control of the impact pressure, a thin buffer plate of the same material as the impact plate is placed in front of the target assembly for symmetrical impact. Also included in the two target assemblies are six tilt pins placed around the periphery of the target flush with the impact surface to measure the tilt of the impact plate as it strikes the target, and two velocity pins sticking out some known distance from the target to measure the velocity of the impact plate just before it strikes the target.

During the experiment, oscilloscopes measure change of voltage as result of resistance change in the gauges which were then converted to pressure using the hysteresis corrected calibration curve published elsewhere (5). From the data of the shock arrival times of the gauge locations, a plot of distance vs. time ("x-t plot") is constructed with the slope of the plotted lines yielding the shock velocities with two lines apparent, a line for the un-reacted state as it reacts and a line representing the detonation velocity. The intersection of these two lines is taken as the "run-distance-to-detonation," which is then plotted on the "Pop-Plot" showing the run-distance-to-detonation as a function of the input pressure in log-log space.

\section{Experimental Records}

Total of 7 shots were fired of which 3 of them were with the C-4 explosives in the disc target configuration and 4 with the Composition B in the wedge target configuration. Densities, impact velocities and pressures imposed on the targets material are listed in Table 1

Table 1. Listing of shock initiation gun experiments

\begin{tabular}{|c|c|c|c|c|c|}
\hline Shot \# & Target & $\begin{array}{c}\text { Density } \\
(\mathrm{g} / \mathrm{cc})\end{array}$ & $\begin{array}{c}\text { Velocity } \\
(\mathrm{km} / \mathrm{s})\end{array}$ & $\begin{array}{c}\text { Pressure } \\
(\mathrm{GPa})\end{array}$ & $\begin{array}{c}\text { Dist. to Det. } \\
(\mathrm{mm})\end{array}$ \\
\hline 4565 & Comp.4 & 1.590 & 0.6 & 2.2 & 25 \\
\hline 4547 & Comp. 4 & 1.630 & 0.737 & 2.86 & 17 \\
\hline 4564 & Comp. 4 & 1.621 & 0.987 & 4.2 & 9 \\
\hline 4359 & Comp. B & & 0.835 & 3.78 & 14 \\
\hline 4544 & Comp. B & 1.692 & 0.929 & 4.35 & 11 \\
\hline 4540 & Comp. B & 1.690 & 1.005 & 4.80 & 10 \\
\hline 4545 & Comp. B & 1.681 & 1.307 & 6.84 & 5 \\
\hline
\end{tabular}

Figure 2 shows pressure records of a shock loaded RDX-based high explosive C-4 (91 weight \% RDX and 9 weight \% of other additives) pressed to 98.5 of theoretical maximum density. The explosive samples in these experiments were shock loaded with an aluminum impactor flying at a velocity of $0.6, \mathrm{~mm} / \mu \mathrm{s}$, imposing a pressure on the target material 2.2 GPa. As in all heterogeneous explosives these traces exhibit the 
characteristic features of their initiation: some reaction occurs just behind the shock front causing it to grow in pressure, but most of the reaction occurs well behind the leading shock, creating a pressure wave that overtakes the initial shock wave causing the process to finally transit to detonation. In this case the transition to detonation occurred at about $25 \mathrm{~mm}$ into the target.

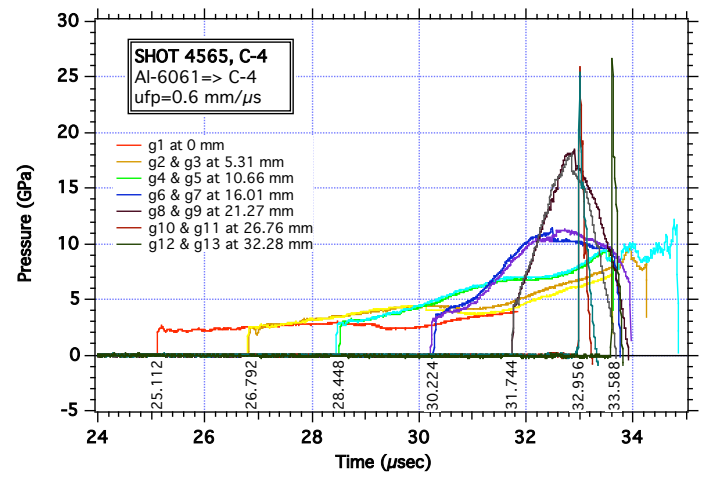

Figure 2. A typical pressure gauge

Figure 3. A typical pressure gauge record for the $\mathrm{C}-4$ material.

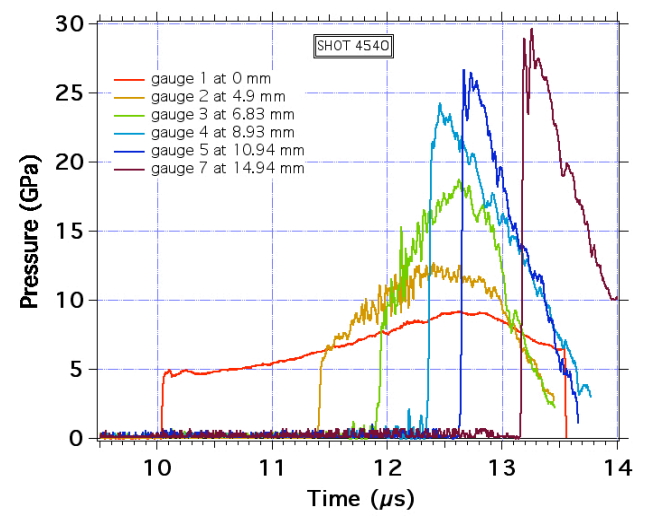

record for the Comp. B material.

Figure 3 illustrates the records obtained with a wedge type experiments performed on another RDX based explosive Composition B (63-weight \% RDX, 36weight $\%$ TNT and 1 weight $\%$ of Wax) at ambient room temperature. It shows initially a steady shock wave and then, after the reaction becomes significant, a strong growth in pressure just before the transition to detonation. The loading pressure in this experiment was $4.8 \mathrm{GPa}$.

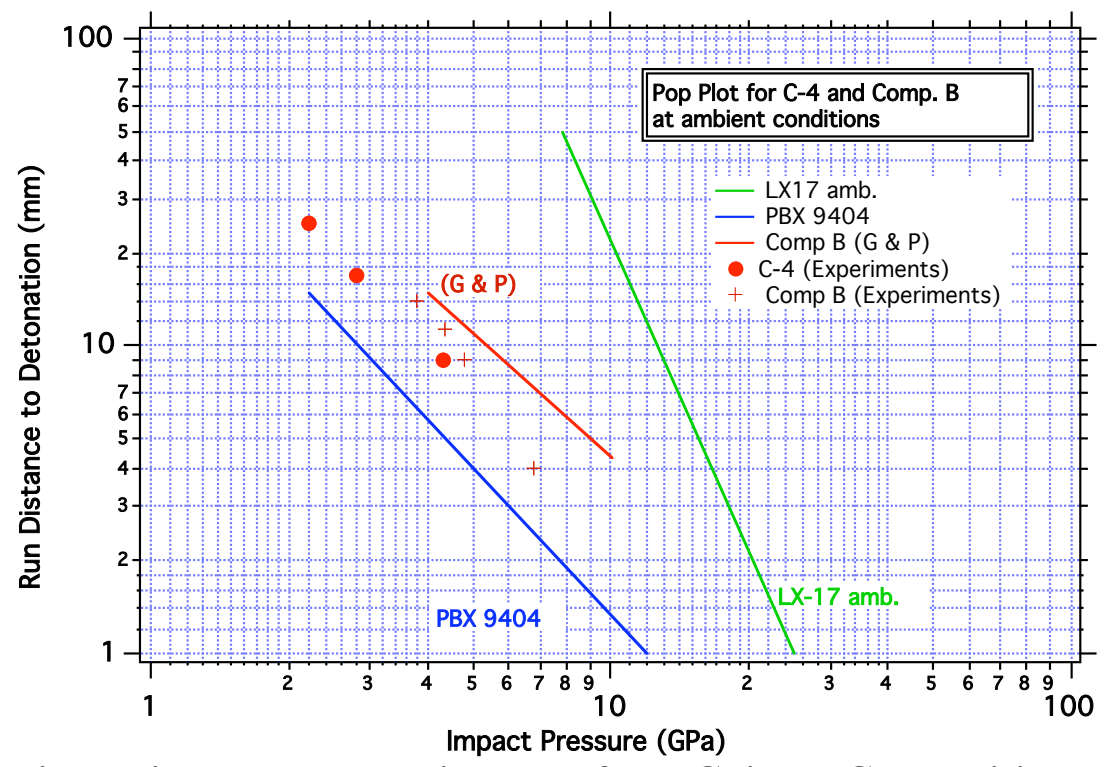

Figure 4. Pop-Plot showing data from $\mathrm{C}-4$ and Composition $B$ along with reference lines for other sensitive and insensitive High Explosives.

Shock sensitivity of both C-4 and Composition B for various initial pressures is illustrated in Fig. 4 on a so-called "Pop Plot", which displays the dependence of the 
distance to detonation on the initial impact pressure. On this plot one can easily compare the relative sensitivity of these explosives to a more sensitive explosive HMX-based PBX 9404 and a TATB based insensitive high explosive at their ambient conditions. On a loglog plot the run distance to detonation versus shock pressure data mostly fall on a straight line. The closer the line is to the origin of the plot, the more sensitive is the material. Shown here are also previously published data of Gibbs and Popolato (6).

\section{Equation of State Analysis}

For any new material that was tested in our laboratory we also determine their experimental equation of state in the form of a new shock velocity- particle velocity $\left(\mathrm{U}_{\mathrm{s}}-\mathrm{u}_{\mathrm{p}}\right)$ relationship. This analysis is done by using the well-known impedance matching technique and is illustrated in Figures 5 and 6 for the case of C-4 and Comp B respectively.

Assuming that the EOS relations of the impactor at room temperature are very well known, one can plot the inverse adiabat of the flyer plate originating at the flyer velocity. Experimental measurement of the initial pressure from several experiments will result in the adiabat of the new target material. Measured shock velocities between the first two or more gauge stations from the same experiments allow one to draw a line through the experimental points in the shock velocity - mass velocity plane and determine the new $U_{s}-u_{p}$ relationship for this material.

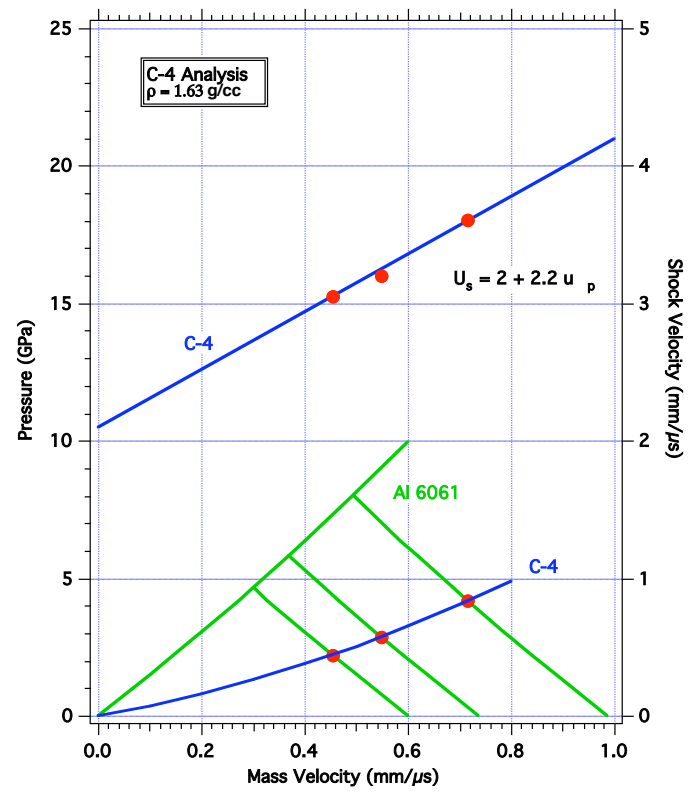

Figure 5. Impedance matching and $\mathrm{U}_{\mathrm{s}}-\mathbf{u}_{\mathrm{p}}$ for C-4.

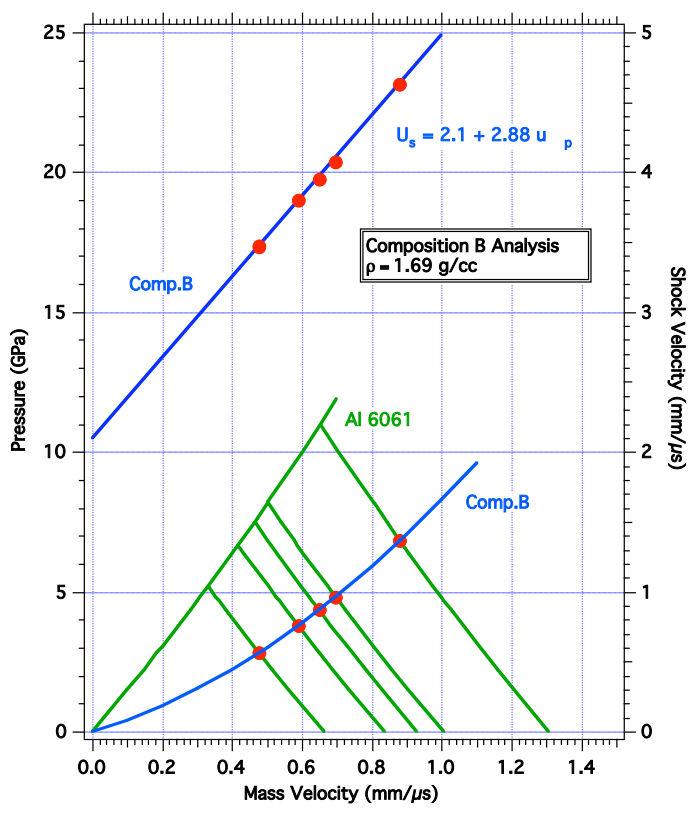

Figure 6. Impedance matching and $\mathrm{U}_{\mathrm{s}}-\mathbf{u}_{\mathrm{p}}$ for Composition $\mathrm{B}$. 


\section{Ignition \& Growth Modeling}

The Ignition and Growth reactive flow model for shock initiation and detonation is described in detail elsewhere (7). Since the embedded pressure gauges require onedimensional flow, the calculations are also one-dimensional and use a mesh size of 50 zones per mm. Since both C-4 and Comp B are RDX-based, they exhibit similar early hot spot formation and growth rates. Thus, the first and second reaction rates are normalized to the C-4 embedded gauge records and then used to model the Comp B records. Also, since Comp B has been demonstrated to undergo shock desensitization in certain situations (8), a value of 0.0367 for the critical compression parameter in the Ignition rate law to prevent ignition below approximately $0.5 \mathrm{GPa}$. The third reaction rate is used to describe the slower reaction of the TNT component of Comp B. Comp B contains approximately $60 \%$ RDX, but, since RDX is more energetic than TNT, $70 \%$ of the chemical energy is assumed to be liberated at the RDX reaction rates and $30 \%$ by the TNT rates. Separating the reaction rates in this manner has been used successfully in previous modeling efforts in which two materials react at sufficiently different rates. Examples include RX-26-AF, which contains half HMX and half TATB (9) and various aluminized explosives, in which aluminum is oxidized by previously formed explosive reaction product gases (10). In the following sections, Ignition and Growth calculations are compared to the measured pressure histories and run distances to detonation for C-4 and Comp B.

\section{C-4 Reactive Flow Modeling}

Figures $7-9$ show the calculated pressure histories in the center zone of each Teflon-coated embedded manganin gauge using the Ignition and Growth parameters for C-4 listed in Table 2 and the equations of state for the aluminum flyers and Teflon gauge packages listed in Table 3 for the three disc shaped targets listed in Table 1 in order of increasing shock pressure. These figures also include experimental traces of pressure (solid lines) for a direct comparison between experiment and calculation. Both, measured and calculated growths of reaction in Fig. 7 agree closely for the lowest shock pressure experiment number 4565 listed in Table 1. The transition to detonation occurs just before the $25 \mathrm{~mm}$ deep gauge,

For the intermediate shock pressure experiment 4547, Fig. 8 shows good agreement for the growth of reaction and the transition distance to detonation, which occurs just after the $15 \mathrm{~mm}$ deep gauge. For the highest shock $\mathrm{C}-4$ experiment number 4564 , the calculated run distance to detonation, which occurs just after the $10 \mathrm{~mm}$ deep gauge (Fig. 8), is slightly longer than the experimental run distance of just less than 10 $\mathrm{mm}$. The calculated growth of reaction at the 0 and $5 \mathrm{~mm}$ deep gauge positions agrees well with the experimental records. Thus, this relatively simple two reaction rate model for $\mathrm{C}-4$ shock initiation agrees quite well with the three sets of pressure history measurements and the run distances to detonation. Further tests of the $\mathrm{C}-4$ parameters can be made if additional experimental data on $\mathrm{C}-4$ becomes available. 
Table 2. Ignition \& Growth parameters for C-4.

\begin{tabular}{|c|c|c|}
\hline A. $25^{\circ} \mathrm{C}$ C- 4 & $\mathrm{r}_{\mathrm{O}}=1.601 \mathrm{~g} / \mathrm{cm}^{3}$ & \\
\hline UNREACTED JWL & PRODUCT JWL & REACTION RATES \\
\hline $\mathrm{A}=778.1 \mathrm{Mbar}$ & $\mathrm{A}=6.0977 \mathrm{Mbar}$ & $\mathrm{I}=4.0 \times 10^{6} \mathrm{~ms}^{-1}$ \\
\hline $\mathrm{B}=-0.05031 \mathrm{Mbar}$ & $\mathrm{B}=0.1295 \mathrm{Mbar}$ & $\mathrm{a}=0.0367$ \\
\hline $\mathrm{R}_{1}=11.3$ & $\mathrm{R}_{1}=4.5$ & $b=0.667$ \\
\hline $\mathrm{R}_{2}=1.13$ & $\mathrm{R}_{2}=1.4$ & $\mathrm{~F}_{\text {igmax }}=0.022$ \\
\hline$\omega=0.8938$ & $\mathrm{w}=0.25$ & $\mathrm{G}_{1}=140 \mathrm{Mbar}^{-2} \mathrm{~ms}^{-1}$ \\
\hline $\mathrm{C}_{\mathrm{V}}=2.487 \times 10^{-5} \mathrm{Mbar} / \mathrm{K}$ & $\mathrm{C}_{\mathrm{V}}=1.0 \times 10^{-5} \mathrm{Mbar} / \mathrm{K}$ & $\mathrm{c}=0.667$ \\
\hline $\mathrm{T}_{\mathrm{O}}=298^{\circ} \mathrm{K}$ & $\mathrm{E}_{\mathrm{O}}=0.09 \mathrm{Mbar}$ & $\mathrm{d}=0.333$ \\
\hline Shear Modulus $=0.0354 \mathrm{Mbar}$ & & $\mathrm{F}_{\mathrm{G} 1 \mathrm{max}}=1.0$ \\
\hline \multirow[t]{3}{*}{ Yield Strength $=0.002 \mathrm{Mbar}$} & & $\mathrm{G}_{2}=0 \mathrm{Mbar}^{-1} \mathrm{~ms}^{-1}$ \\
\hline & & $\mathrm{e}=0.667$ \\
\hline & & $\mathrm{g}=0.667 \mathrm{FG} 2 \mathrm{~min}=0.0$ \\
\hline
\end{tabular}

Table 3. Gruneisen Equation of State parameters for inert materials

$$
\begin{array}{r}
\left.\mathrm{P}=\mathrm{r}_{\mathrm{o}} \mathrm{c}^{2} \mathrm{~m}\left[1+\left(\tilde{1} \mathrm{~g}_{\mathrm{o}} / 2\right) \mathrm{m}-\mathrm{a} / 2 \mathrm{~m}^{2}\right] /\left[1-\left(\mathrm{S}_{1}-1\right) \mathrm{m}-\mathrm{S}_{2} \mathrm{~m}^{2} /(\mathrm{m}+1)-\mathrm{S}_{3} \mathrm{~m}^{3} /(\mathrm{m}+1)^{2}\right]^{2}+\mathrm{g}_{\mathrm{o}}+\mathrm{am}\right) \mathrm{E}, \\
\text { where } \left.\mathrm{m}=\tilde{\sim} \mathrm{rr}_{\mathrm{o}}-1\right) \text { and } \mathrm{E} \text { is thermal energy }
\end{array}
$$

\begin{tabular}{|c|c|c|c|c|c|c|c|}
\hline INERT & $\varrho_{\mathrm{o}}\left(\mathrm{g} / \mathrm{cm}^{3}\right)$ & $\underline{\mathrm{c}(\mathrm{mm} / \mu \mathrm{s})}$ & $\underline{S}_{1}$ & $\underline{S}_{2}$ & $\underline{S}_{3}$ & $x_{0}$ & $\underline{\mathrm{a}}$ \\
\hline $\mathrm{Al} 6061$ & 2.703 & 5.24 & 1.4 & 0.0 & 0.0 & 1.97 & 0.48 \\
\hline Teflon & 2.15 & 1.68 & 1.123 & 3.983 & -5.797 & 0.59 & 0.0 \\
\hline Steel & 7.90 & 4.57 & 1.49 & 0.0 & 0.0 & 1.93 & 0.5 \\
\hline PMMA & 1.182 & 2.18 & 2.088 & -1.124 & 0.0 & 0.85 & 0.0 \\
\hline Brass & 8.45 & 3.834 & 1.43 & 0.0 & 0.0 & 2.0 & 0.0 \\
\hline HDPE & 0.954 & 3.0 & 1.44 & 0.0 & 0.0 & 1.0 & 0.0 \\
\hline
\end{tabular}

\begin{tabular}{|c|c|c|c|}
\hline \multicolumn{4}{|c|}{$\rho_{\mathrm{o}}=1.717 \mathrm{~g} / \mathrm{cm}^{3}$} \\
\hline UNREACTED JWL & PRODUCT JWL & \multicolumn{2}{|c|}{ REACTION RATES } \\
\hline $\mathrm{A}=778.1 \mathrm{Mbar}$ & $\mathrm{A}=5.242 \mathrm{Mbar}$ & \multicolumn{2}{|c|}{$\mathrm{I}=4.0 \times 10^{6} \mu \mathrm{s}^{-1}$} \\
\hline $\mathrm{B}=-0.05031 \mathrm{Mbar}$ & $\mathrm{B}=0.07678 \mathrm{Mbar}$ & \multicolumn{2}{|l|}{$a=0.0367$} \\
\hline $\mathrm{R}_{1}=11.3$ & $\mathrm{R}_{1}=4.2$ & \multicolumn{2}{|l|}{$b=0.667$} \\
\hline $\mathrm{R}_{2}=1.13$ & $\mathrm{R}_{2}=1.1$ & $\mathrm{x}=7.0$ & $\mathrm{~F}_{\text {igmax }}=0.022$ \\
\hline$\omega=0.8938$ & $\omega=0.5$ & \multicolumn{2}{|c|}{$\mathrm{G}_{1}=140 \mathrm{Mbar}^{-2} \mu \mathrm{s}^{-1}$} \\
\hline $\mathrm{C}_{\mathrm{V}}=2.487 \times 10^{-5} \mathrm{Mbar} / \mathrm{K}$ & $\mathrm{C}_{\mathrm{V}}=1.0 \times 10^{-5} \mathrm{Mbar} / \mathrm{K}$ & \multicolumn{2}{|l|}{$\mathrm{c}=0.667$} \\
\hline $\mathrm{T}_{\mathrm{O}}=298^{\circ} \mathrm{K}$ & $\mathrm{E}_{\mathrm{O}}=0.085 \mathrm{Mbar}$ & \multicolumn{2}{|l|}{$\mathrm{d}=0.333$} \\
\hline \multicolumn{2}{|c|}{ Shear Modulus $=0.0354 \mathrm{Mbar}$} & $\mathrm{y}=2.0$ & $\mathrm{~F}_{\mathrm{G} 1 \mathrm{max}}=0.7$ \\
\hline \multirow{2}{*}{\multicolumn{2}{|c|}{ Yield Strength $=0.002 \mathrm{Mbar}$}} & \multicolumn{2}{|c|}{$\mathrm{G}_{2}=1000 \mathrm{Mbar}^{-1} \mu \mathrm{s}^{-1}$} \\
\hline & & $\begin{array}{l}\mathrm{e}=0.222 \\
\mathrm{~g}=1.0\end{array}$ & $\begin{array}{l}\mathrm{z}=3.0 \\
F_{\mathrm{G} 2 \min }=0.0\end{array}$ \\
\hline
\end{tabular}

Table 4. Ignition \& Growth parameters for Comp B 


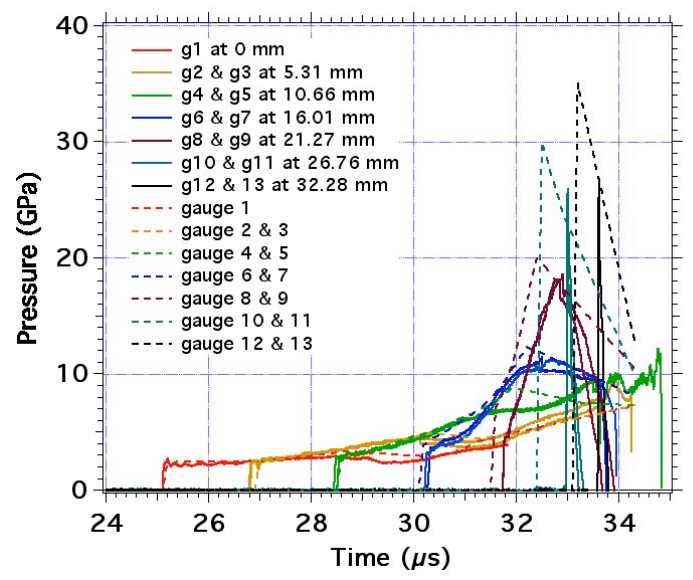

Figure 7. Calculated Pressure

histories for C-4 impacted by an

aluminum flyer at $0.6 \mathrm{~km} / \mathrm{s}$

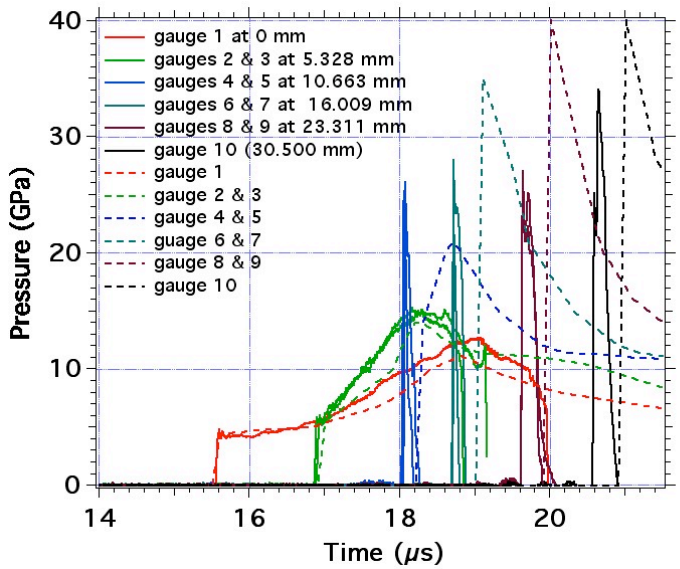

Figure 9. Calculated pressure histories

for C-4 Impacted by an aluminum flyer

at $0.6 \mathrm{~km} / \mathrm{s} 0.987 \mathrm{~km} / \mathrm{s}$

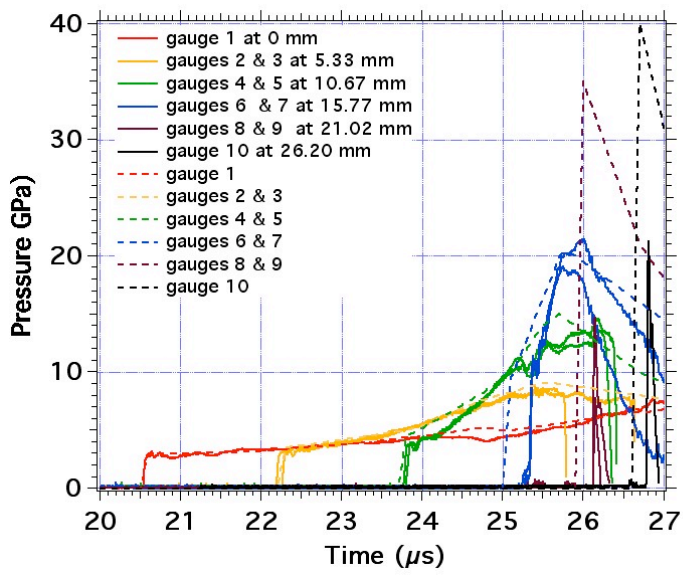

Figure 8. Calculated pressure histories for C-4 impacted by an aluminum flyer at $0.737 \mathrm{~km} / \mathrm{s}$

\section{Comp B Reactive Flow Modeling}

Four Comp B embedded gauge experiments using wedge shaped targets are listed in Table 1. The resulting embedded manganin gauge pressure histories and their corresponding calculated pressure histories are shown in Figs. 10 - 13 in order of increasing shock pressure. The model parameters for Comp B parameters are listed in Table 4. For the lowest shock pressure shot 4359, Fig.10 shows good agreement for the growth of reaction at the $0,4.5,7.75$, and $11.01 \mathrm{~mm}$ gauge positions and for detonation at the $17.51 \mathrm{~mm}$ and $20.77 \mathrm{~mm}$ depths. For the next highest shock pressure shot $4544 \mathrm{using}$ an aluminum flyer plate at $0.929 \mathrm{~km} / \mathrm{s}$, Fig. 11 shows good agreement between 
experimental and calculated pressure histories at the first 5 embedded gauges and transition to detonation before the 11.91 and $12.92 \mathrm{~mm}$ deep gauges.

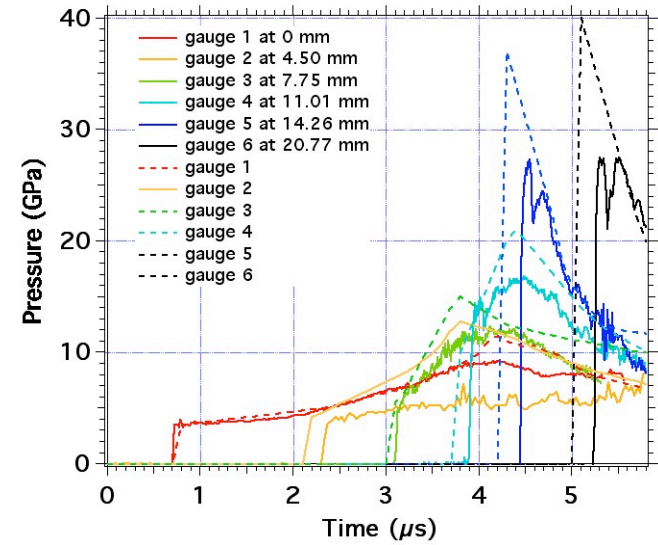

Figure 10. Calculated pressure histories for Comp B impacted by an aluminum flyer at $0.835 \mathrm{~km} / \mathrm{s}$

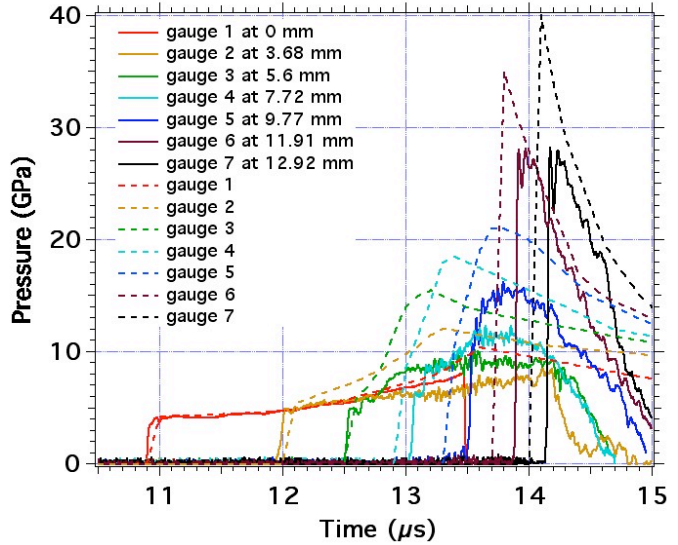

Figure 11. Calculated pressure histories for Comp B impacted aluminumflyer at $0.929 \mathrm{~km} / \mathrm{s}$

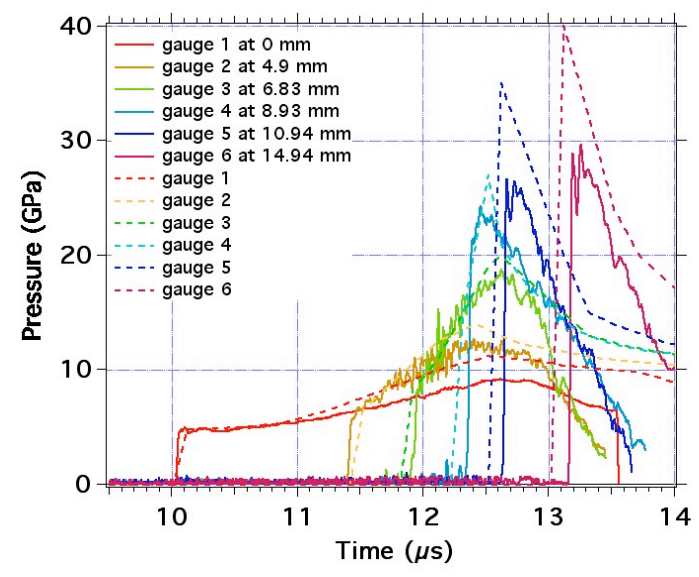

Figure 12. Calculated Pressure Histories for Comp B Impacted by an Aluminum Flyer at $1.005 \mathrm{~km} / \mathrm{s}$

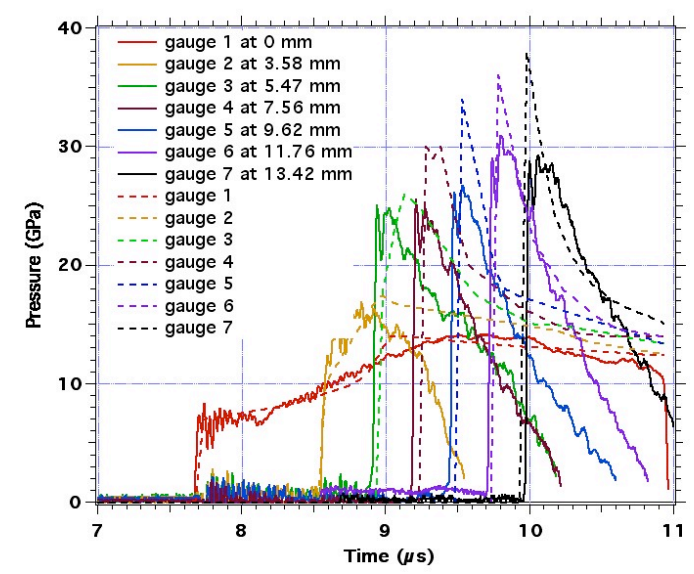

Figure 13. Calculated Pressure Histories for Comp B Impacted by an Aluminum Flyer at $1.307 \mathrm{~km} / \mathrm{s}$

For the second highest pressure shot 4540, Fig.12 exhibits good agreement between the measured and calculated pressure histories at the first four gauge positions and for detonation at the $10.94 \mathrm{~mm}$ and $14.94 \mathrm{~mm}$ gauge depths. For the highest shock pressure shot 4545 , the measured distance to detonation is slightly less than the $5.47 \mathrm{~mm}$ deep gauge position, while the calculated transition occurs just after the $5.47 \mathrm{~mm}$ gauge, as shown in Fig. 13. The measured and calculated reaction growths at the $0 \mathrm{~mm}$ and 3.58 $\mathrm{mm}$ deep gauges agree very well. As mentioned for C-4, a slightly faster transition to detonation rate at high shock pressures is needed for better agreement. 


\section{Conclusions}

Embedded manganin pressure gauge records and run distances to detonation were measured at various shock pressures for the RDX-based explosives C-4 and Comp B. This experimental data was used to determine reaction rate parameters for the Ignition and Growth model. The same ignition and growth rate coefficients were used for both explosives. A third reaction rate was then used to simulate the slower TNT reaction rate within the Comp B model. This Comp B model can be used to predict other shock initiation scenarios that have not or can not be experimentally tested directly with a high degree of confidence,

\section{Acknowledgements}

The authors would like to thank the $101 \mathrm{~mm}$ powder gun crew for all their hard work in obtaining the embedded pressure gauge records.

\section{References}

1. Forbes, J. W., Tarver, C. M., Urtiew, P. A., and Garcia, F., Eleventh International Detonation Symposium, Office of Naval Research ONR 33300-5, Aspen, CO, 1998, p. 145 .

2. Urtiew, P. A., Forbes, J. W., Tarver, C. M., Vandersall, K. S., Garcia, F., Greenwood, D. W., Hsu. P. C., and Maienschein, J. L., Shock Compression of Condensed Matter - 2003, AIP Confernece Proceedings 706, AIP Press, New York, 2004, p. 1053.

3. Vantine H., Chan J., Erickson L. M., Janzen J., Lee R. and Weingart R. C., "Precision Stress Measurements in Severe Shock-Wave Environments with Low Impedance Manganin Gauges," Rev. Sci. Instr., 51. pp. 116-122 (1980).

4. P.A. Urtiew, L.M. Erickson, B. Hayes, and N.L. Parker "Pressure and Particle Velocity Measurements in Solids Subjected to Dynamic Loading," Fizika Gorenia i Vzryva, (in Russian) 22, No. 5, pp. 113-126, 1986. Translation in Combustion, Explosion and Shock Waves, 22, No. 5, pp. 597-614, 1986.

5. Vantine, H.C., Erickson, L.M. and Janzen, J., "Hysteresis-Corrected Calibration of Manganin under Shock Loading", J. Appl. Phys., 51 (4), April 1980.

6. Gibbs, T.R. and Popolato, A., LASL Explosive Property Data, p.19, University of California Press, Berkeley, CA, 1980 
7. Tarver, C. M., Lefrancois, A. S., Lee, R. S. and Vandersall, K. S., "Shock initiation of the PETN-based Explosive LX-16," Presented at the Thirteenth international Detonation Symposium, which was held in Norfolk, VA, July 21-28, 2006.

8. Campbell, A. W. and Travis, J. R., "The Shock Desensitization of PBX 9404 and Composition B-3," Eighth Symposium (International) on Detonation, Naval Surface Weapons Center NSWC 86-194, Albuquerque, NM, 1985, p. 1057.

9. Tarver, C. M., Erickson, L. M. and Parker, N. L., "Shock Initiation, Detonation Wave Propagation and Metal Acceleration Measurements and Calculations for RX-26-AF," Shock Waves in Condensed Matter - 1983, J. R. Asay, R. A. Graham, and G. K. Straub, eds., North Holland Physics Publishing, Amsterdam, 1984, p. 609.

10. Tao, W. C., Tarver, C. M., Kury, J. W., Lee, C. G. and Ornellas, D. L."Understanding Composite Explosive Energetics IV: Reactive Flow Modeling of Aluminum Reaction Kinetics in PETN and TNT Using Normalized Product Equation of State," Tenth International Detonation Symposium, Office of the Chief of Naval Research OCNR 33395-12, Boston, MA, 1993, p. 628. 